\title{
Contextual Analysis of Educational Monitoring and Progression as a Service (EMPaaS) System in Higher Education
}

\author{
Mohammed Ali' ${ }^{1}$, Trevor Wood-Harper ${ }^{1}$, Abdullah Sultan Al-Gahtani ${ }^{2}$ \\ ${ }^{1}$ Innovation Management and Policy Division, Alliance Manchester Business School, University of Manchester, Manchester, UK \\ ${ }^{2}$ Knowledge Management Division, Research and Knowledge Exchange, Manchester Metropolitan University, UK Academic \\ Consultations Ltd., Manchester, UK \\ Email: mohammed.ali@manchester.ac.uk, atwh@manchester.ac.uk, Abdullah@ukaconsultations.com
}

How to cite this paper: Ali, M., WoodHarper, T. and Al-Gahtani, A.S. (2019) Contextual Analysis of Educational Monitoring and Progression as a Service (EMPaaS) System in Higher Education. Open Journal of Business and Management, 7 , 1525-1542.

https://doi.org/10.4236/ojbm.2019.73105

Received: July 1, 2019

Accepted: July 27, 2019

Published: July 30, 2019

Copyright $\odot 2019$ by author(s) and Scientific Research Publishing Inc. This work is licensed under the Creative Commons Attribution International License (CC BY 4.0).

http://creativecommons.org/licenses/by/4.0/

\begin{abstract}
The arrival of new technologies has opened a window of opportunity for UK higher education institutions. Although UK Higher education (HE) has recently become a huge phenomenon owing to an increase in students attending University, many UK universities are not investing enough in technology to facilitate teaching, management and research practices that aim to improve the student experience. This paper discusses the potential for an information system solution, which can facilitate the institutional practices in UK HEIs from multiple stakeholder perspectives. An existing system employed at a UK University known as "MyPGR" was evaluated in order to shed some light on the existing technical problems UK Universities are currently facing, with the support of a soft systems approach (CATWOE). The proposed solution is the Educational-Monitoring-and-Progression-as-a-Service (EMPaaS), which is based on the Cloud Computing model. EMPaaS has the potential to monitor student progression and key milestones relating to their PGR programme, in addition to enabling students to use free cloud applications to keep track of milestones and progressions. The highly accessible and flexible nature of cloud applications adds to the cost-effectiveness of adopting cloud services, which in turn frees up additional funds for UK Universities to pursue other important investments.
\end{abstract}

\section{Keywords}

Exploring Monitoring, Progression System, Higher Education, Multiple Perspectives, EMPaaS 


\section{Introduction}

Today, UK Higher education (HE) has become a huge phenomenon. This is mostly down to UK HE, in recent times attracting foreign investment from international students, as well as providing a better education, skills and experiences that their native country cannot provide. There have been major changes for UK higher education [1]. The reduction of public funding has been a continuous process across the British Isles, as well as an economic downturn, which saw a new undergraduate funding system being introduced. Furthermore, other political, legal and economic influences have made it difficult to study in UK HE. Some of the most significant issues being increased tuition fees, changes in the UK Border Agency regulations and the UK's decision to leave the European Union [2], which are now beginning to restrict students the right to a decent education. These issues will also affect UK HEIs as a lack of funding, which may affect UK HEIs, leading to potential cutbacks, thus hindering the level of teaching and research UK HEIs can provide [3].

With the arrival of new technologies has opened a window of opportunity for universities across the UK [4]. Grove [5] found that many UK universities are not investing enough in technology to improve students' studies. This also includes the provision of learning material, and makes teaching more effective by providing teachers better learning materials and effective teaching technologies, to support administration in their administrative duties, such as recruitment, registration and responding to staff/student queries, which are often delayed due to a lack of facilities. All of these issues stem from the reluctance of utilising technology to integrate and enhance administration, staff and student support [6]. These areas remain dependent on numerous IT platforms for different services. Therefore, increasing stakeholder demands and expectations, as well as providing efficient and integrated IT systems can warrant an administrative process that is much smoother and cost-efficient. For those reasons, this paper discusses the potential for an information system solution, which can facilitate the teaching, research and management processes in UK HEIs from multiple perspectives in an attempt to tackle the existing problems facing these institutions. This will be supported by a case University.

\section{Significance of Higher Education}

As many UK universities contemplate their economic future, there are some highly significant facts that demonstrate the effective nature of UK higher education. In 2015, Lock [7] cites that there are 3.5 billion worth of research collaborations between UK universities and businesses in various fields, with humanities, arts and engineering being the most common. This demonstrates the quality nature of UK HE. In 2016, Jackson [8] found that Universities are huge contributors to the UK economy with the UK HEI sector contributing an additional 4\% GDP in 2016 because of the number of students enrolling at University doubling. In 2018, it was estimated that almost 3 million students enrolled in 
UK higher education [9]. In terms of University rankings, the UK currently has four institutions in the world's top ten ranked universities in 2019: University of Oxford (ranked forth); University of Cambridge (ranked seventh); University of College London (ranked eighth); and Imperial College London (ranked ninth) [10]. Despite having a reasonable number of institutions being ranked in the top ten of the world's most prestigious universities, tuition fees and UK border agency policies have become a growing concern for UK students seeking higher education, which will be discussed in later sections.

For students, particularly international students, the UK HEI sector provides them with a better quality education that will allow them to compete for higher quality jobs with better salaries. This shows that the most alumni have a very positive experience, and obtain various skills and experiences to support their future careers or future post-graduate studies [3]. A mixture of good experiences and positive views of UK HE, its people and culture, can even lead to an emotional bond between the UK and alumni, thereby increasing UKs power of soft diplomacy and trust among international business collaborations [11]. Most international students' intention to study in UK HE is not solely down to migrating to the UK or seeking long-term employment, but it is so they can acquire a better education that can equip them with the skills they need to work in their native country, since many international students come from countries with poor education systems. Not only that, it gives them the experience to study in a culture that they are unfamiliar with, which helps them to obtain further skills and experiences that can boost their career prospects.

\section{Technical Challenges Facing UK Higher Education}

UK universities always aim to improve their operations to reduce their expenditures and compete with other universities through investing and adopting recent technologies and meet global standards. Nevertheless, there is still hope for UK $\mathrm{HE}$ as the need for cheaper and flexible emerging technologies, such as cloud computing (CC), to support teaching and research is on the rise, thereby helping HEIs to overcome future challenges [12]. The financial problems explained above limit universities ability to invest in new projects and gain new technologies. This also creates an additional barrier that hinders universities from competing in new and adapting markets, according to the Department for Innovation, Universities and Skills [13]. This also includes other factors such as low digital fluency among faculty (lack of IT skills), failing to adopt modern technologies to support teaching and research, and a lack of collaboration between IT and non-IT departments [14]. Therefore, universities now are under pressure to find possible solutions that overcome above discussed challenges.

Focusing on emerging technologies can help to explore how technological innovation could affect the resistance within UK HEIs given internal staffs lack of skills of using technology or their dissatisfaction with existing technologies embedded within the institution [15]. The introduction of new emerging technolo- 
gies shows the potential to change how education is conceived and delivered. In addition, despite millions being invested in technology for enhancing teaching, learning and research at UK HE, there is very little evidence to support that such technologies are effective in these areas [16]. Therefore, the main argument here is that existing technologies within UK HEIs are insufficient and require radical change and how new emerging technologies within the institution can overcome the existing barriers they face to enhance their teaching and research.

Overall, these challenges negatively affect universities budgets and limiting their capabilities for making new investments, improving operations and attracting talented researchers. This reflects on universities ability to keep delivering competitive quality of education services and researches, which may result in their reputation that they have built over a considerable period becoming tarnished. This also reflects on the quality of IS the institution has in developing their education services, and thus there is a need to improve existing IS within these institutions. The section evaluates an existing information system employed at a UK University known as "MyPGR" in order to provide insight into the existing technical problems UK Universities are currently facing, with the support of a soft systems approach (CATWOE) from multiple perspectives (multiview 3).

\section{Deployment Models}

MyPGR is a University-wide online progression system, which supports both students and academic staff throughout the post-graduate (PGR) programme. It has the ability to break down each of the programmes requirements into manageable goals, as well as facilitating the planning of achievable targets. In addition, MyPGR allows both students and staff to note and reflect on current progress made throughout the PGR programme against previously agreed milestones and deadlines. MyPGR also comes with an online user interface to enable academic staff and administrators to note and track students' progress and milestones throughout the PGR programme from the time of registration to completion via submission and examination. In short, MyPGR is an online progression and monitoring tool that enables students to monitor and update their progress on demand, anytime, anywhere, in addition to providing upload services to manage documents to share with academic staff.

\subsection{Current Problem with MyPGR}

The case University have voiced their concerns about the existing MyPGR system. For example, in 2014, academic and administrative staff reported slow load times on MyPGRs pages, and has deteriorated ever since. Poor performance is not the only issue affecting the system, but other general problems as well. Staff and students have reported save errors on submission pages where students lose progress and filled fields on forms, as well as the system timing out on occasion. There have even been cases of non-accessibility of the system, thus preventing 
users from saving their progress. Since PGR students rely on this system to exchange information, as well as monitor and update their progress, they rely on its features to operate to their needs. Both students and academic staff are beginning to reject the system due to its flaws ranging from poor performance to inconvenience. Therefore, to determine the viability and relatability of the existing MyPGR system, the next section provides an evaluation of the system, which will discuss its key strengths and weaknesses.

\subsection{CATWOE Evaluation of MyPGR from Multiple Perspectives}

The founder of the Soft Systems Methodology (SSM) Peter Checkland and Brian Wilson defined a CATWOE as a simple checklist for systems thinking, and to stimulate an open thought model [17] [18] [19]. SSM is simply the application of a hard systems approach to resolve business-related problems. Both Checkland and Wilson found a problem at the first step of the problem definition, since different stakeholders have different views on what a system actually is its purpose and the problem. Both Checkland and Wilson through action research had developed a practical and pragmatic approach to identify and provide a solution for soft ill-defined problems [20].

CATWOE is essentially a key process of the SSM model [17] [19], which helps to define a root definition. This is a statement of purpose, which merely encapsulates a particular situation of an appropriate system [21]. Since MyPGR is an information system that caters to multiple stakeholders, it would be more logical to define the world view first as this provides a background of MyPGR, and then define the systems processes, customers, actors, owners and environmental constraints (WTCAOE). This provides a much richer and logical picture of the use of MyPGR from multiple stakeholder perspectives.

Worldview: The worldview is essentially the purpose of using MyPGR or why customers, actors and owners use the system [20]. In other words, the value individuals place in the MyPGR system provides the justification as to why (or why not) individuals use such systems, and the ways to use them. From a student perspective, MyPGR is an online tool, which helps them to monitor and update their progress on demand, as well as uploading services to manage documents to share with academic staff, anytime, anywhere. Students consider MyPGR as a highly accessible and flexible system, which enables them to share their current progress throughout their PGR programme with their supervisors. From a supervisory perspective, on the other hand, MyPGR is a system, which allows them to oversee and monitor their students' progress, and alert them about future events relevant to their PGR programme. Supervisors consider MyPGR as a system, which creates a collaborative environment for both themselves and their students to share information and communicate openly about any issues related to the PGR programme. In contrast, IT managers and admins view MyPGR as a highly assessable and flexible monitoring and progression tool, which enables both students and supervisors to communicate online about various issues related to the PGR programme in which they are affiliated. Con- 
sidering the recent complaints regarding the accessibility of MyPGR, the worldview as to why stakeholders would reject the system was down to poor loading times, as well as system bugs, which led to students' progress being lost. Therefore, MyPGR must meet the needs of their key stakeholders in terms of accessibility and usability in order to facilitate the process of the PGR programme for both students and supervisors.

Transformation: Checkland [17] pointed out that transformation is the primary processes of a business that converts inputs into outputs. In terms of MyPGR, transformation is essentially the University's primary processes, which are affected by the MyPGR system to deliver an intended outcome. For example, stakeholders would expect the MyPGR system to be highly accessible and flexible to meet their intended needs. From a student and supervisory perspective, this would involve a system, which has reasonable loading times, good navigation, good structure, and colour schemes and free from noticeable bugs and glitches in order to enhance their online experience of using MyPGR. Similarly, IT managers and admins would also wish MyPGR to be as assessable and useable as possible as these stakeholders influence such outputs. Admins have a duty to assist faculty managers and academic staff, handle student admissions and oversee the system, and thus would want a system that they can readily use without an issue; good usability and accessibility influences these processes. IT managers are obligated to ensure that MyPGR is a highly accessible and usable system, since it is their role to implement the system and oversee the technical issues, such as reducing bugs, increasing loading times, to ensure a good system structure and to ensure that the systems tools are fully functional. Therefore, IT managers and admins shape the University's process to provide a highly accessible and flexible MyPGR system, which enables students and staff to easily update and monitor progress related to their PGR programme.

Customers: Customers are essentially those individuals who use and benefit from the MyPGR system [21]. Students and supervisors are the main the users and beneficiaries of the system. Supervisors merely use MyPGR to oversee students' progress and to plan the yearly progression schedule. They alert students about key milestones and deadlines, as well as other important events, such as mid-year and annual progression reviews in terms of students' research. Students provide their updates, the supervisor then provides feedback, and either approves/declines the students' admission to the next phase of the research according to their overall progress. Students, on the other hand, use MyPGR to upload current documentation relating to their research and to update their supervisor on key milestones and overall progress. Students also use MyPGR to assess how far they have met their intended milestones and serves as a reminder for up and coming events and training course related to their research and PGR programme.

Actors: Checkland [18] describes that actors are those individuals who are involved with the system and how these actors influence the success of the system. The actors of the University's MyPGR system are admins and IT managers 
who oversee and manage it. Despite some individuals having (in terms of their position) a dual function in the CATWOE model, being both an actor or a customer of the trans-formation activities, these individuals are considered actors as all are monitoring, managing, sharing and processing information on MyPGR. Admins, in particular, represent the interests of staff members in the University's business school. Their role includes offering assistance to faculty managers and academic staff and overseeing the system, and thus needs a high level of skills and knowledge of information systems, or in this case, MyPGR. IT managers, on the other hand are required to manage MyPGRs operations and processes in the Business School. To ensure quality assurance via efficient staff and student-oriented support services, IT managers also rely on appropriate file and information management tools. IT managers also look to see improvements in MyPGR, although they did think that a new system would be more appropriate given the number of concerns express by other stakeholders.

Owners: Owners are essentially those individuals who own the process or situation Checkland [18]. In terms of MyPGR, the owner would be the organisation that supplied the University with the MyPGR system and those organisations who have rights to the system. The University, as well as the system vendors are the key owners of MyPGR. Specific users, such as admins, heads of department, IT managers, faculty managers, resource managers and business school executives would also be considered owners of the system, since they have the power to influence the method of working with MyPGR. In other words, IT managers in particular, can be considered owners in MyPGRs environment with the power to influence and intervene in the Business schools approach of IT systems and resources.

Environment: The environment is the external constraints and limitations that will affect the solution and its success [21]. In terms of MyPGR, the laws and regulations that govern the system, as well as privacy acts, which protect the legal storage of student work, can frame this. The university exam board and administrative regulations and restrictions, as well as the higher education and assessment standards, would also be considered as the environment. The UK higher education and assessment standards, in particular, and its requirements on the PGR programme are viewed as an external environmental factor from the perspective of faculty members. Admins, on the other hand, consider law with its privacy regulations as an external environmental factor.

MyPGR and available software resources coupled with appropriate and professional IT managers to support the system are the main influencing internal environmental stakeholders. The environment influencing the use of information systems at the Business School is referred primarily to external bodies such as the higher education and assessment standards and its legal legislations, technology and competitors. Diversity within teams and the different perceptions of different stakeholder roles, and the Business Schools environment lead to an insufficient use of IT resources to create a knowledge-sharing environment. This 
might explain the lack of support and rejection of MyPGR, as the system is currently failing to meet such needs.

Root Definition and Summary: In summary, based on the above CATWOE elements, the root definition of the existing MyPGR system can be described as the following:

A privately owned and supplied system operated by IT managers and administrative staff to support students and supervisory staff to effectively collaborate, as well as assess, monitor and update progress, namely research goals and milestones relevant to their respected PGR programme within the constraints of the $U K$ higher education and assessment standards, privacy laws and regulations.

In general, it can be deduced that MyPGR is useful for monitoring PGR students' progression, but poor loading times or performance problems and a lack of functionality in terms of updating progression forms and loss of data were the most common issues leading to the rejection of MyPGR. This calls for a system that can still encourage collaboration between students and supervisors, as well as employing the same progression tools, but with the added accessibility, useably and trust, which the current MyPGR system lacks. The University is in the process of changing their current progression tool from MyPGR to another system, which would hope to achieve users' accessibility and usability needs going forward. Figure 1 provides a rich picture of the MyPGR system from multiple perspectives.

In summary, MyPGR is a one of a kind system that has been utilised in a minority of Universities to help students and supervisors to collaborate effectively, as well as to manage and monitor progression in terms of working towards goals and milestones on their respected PGR programme. The system is currently facing difficulty, particularly at the University, given the lack of accessibility, leading to a complete rejection of the system. The researcher proposes cloud computing (CC) as a potential solution to the current problems facing the MyPGR system. This is because the technology can not only act as a monitoring and progression system, it can also be a system that can influence collaborative learning between various stakeholders, such as teachers, admins, students and IT staff, as well as supporting other teaching, management and research processes in UK HEIs, such as Universities. The next sections introduce the concept of CC and its application in the UK HEI context.

\subsection{Potential System Solution}

In short, the literature has yet to determine the full extent of the above barriers and drivers from a doctoral student perspective, and in terms of the specific technical, organisational and environmental aspects that influence these barriers and drivers. There also needs to be more success cases like the ones at the University of Westminster [22], but due to the unfamiliarity of CC among HEIs, as well as the challenges that could potentially hinder their IS development, is still a key issue within the HE sector. Therefore, this paper uses the TOE model to pin 


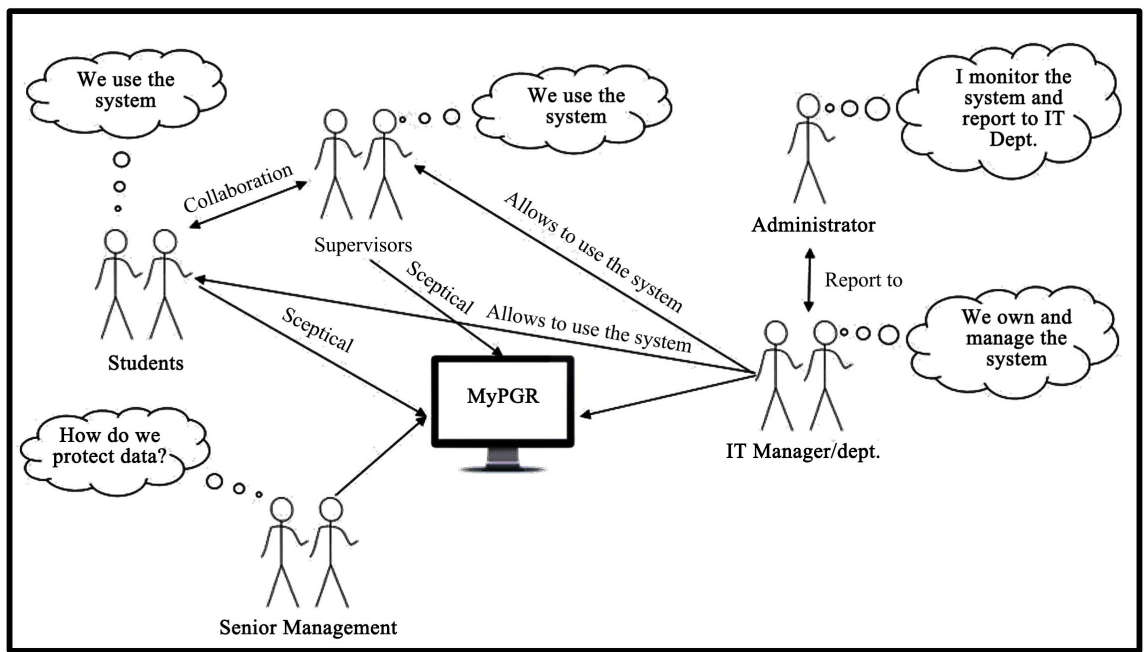

Figure 1. Rich picture of existing mypgr system processes from multiple perspectives, showcasing collaborative processes between departments.

point the specific barriers and drivers that relate to the educational cloud from a doctoral student perspective using the already identified drivers and barriers from the existing literature.

Cloud Computing (CC) has been widely interpreted by a number of authors and scholars. Mell and Grance [23] of the National Institute of Standards and Technology (NIST), for example, define CC as a model for enabling ubiquitous, convenient, on-demand network access to a shared pool of configurable computing resources (e.g. networks, servers, storage, applications, and services) that can be provisioned and released with minimal management effort or service provider interaction. Currently, this definition is considered one of the most significant and widely quoted interpretations of CC to date.

The CC model derives from several technologies, including the internet, web services, utility computing, grid computing and virtualisation. Low cost broadband and storage, as well as high-speed wireless networks are all contributing factors toward the development of CC [24]. Furthermore, CC is more than just outsourcing. Youssef and Alageel [25] defines five key characteristics of CC:

Broad Network Access: the ability to access network resources on numerous computing devices ranging from computers to smart phones [26] [27] [28] [29];

Dn-demand Self-Service: the ability to access cloud resources, such as email, applications, storage etc. anytime, anywhere [26] [27] [28] [29];

> Measured Service: paying only for the amount service used [23] [29] [30];

$>$ Rapid Elasticity: measures how far cloud resources are capable of adjusting to changing consumer demands [29] [31];

Resource Pooling: consumption of shared resources over a network, and service providers use shared computing resources to offer customers cloud services [26] [27] [28] [29];

The literature has also identified three key cloud service models and three 
key cloud deployment models [23]:

Service Models:

Software as a Service (SaaS): cloud vendors host applications; which customers can access over a network;

Platform as a Service (PaaS): enables customers to develop, run, and manage web applications without the need of establishing and maintaining the infrastructure associated with application development and execution;

Infrastructure as a Service (IaaS): this is the entire infrastructure stack, and offers visualised resources online or via a network [23] [29] [32] [33].

\section{Deployment Models:}

Public cloud: users can access of pool of resources such as applications, databases and storage using web services or applications publicly or via the Internet [29] [34]. Public clouds are the most commonly used deployment models in educational institutions given they are the cheapest and most flexible option;

Private cloud: these are privately operated clouds for sole organisations, and have the ability to operate and manage the cloud on and off-campus [32]. Private clouds are considered the most secure cloud model given its extra level of security;

Dybrid Cloud: this is a combination of two or more clouds e.g. public and private [29] [32];

> Community Cloud: these are controlled and shared in the cloud environment by various organisations, and caters for a particular community who have similar interests [23] [29] [32] [33].

Currently, there are a number of cloud services on the market, including email services, GoogleApps, ERP systems and CRM Salesforce [28]. CC venders are now targeting higher education institutions (HEIs) [35]. Within the HE arena, CC takes on a completely new definition.

\section{Benefits and Opportunities of Cloud Computing for Higher Education}

Today, technology is influencing and changing the way educational institutions are performing their daily activities and processes. Contemporary education is beginning to take on a more hands-on approach to learning than being confined to traditional classroom learning. Not only that, educational institutions are facing various challenges given the stiff competition between other institutions, while trying to satisfy stakeholders differing needs. Universities, for example, are beginning to take interest in investing in technology for providing quicker and contemporary information technologies for their students. CC is one of these technologies that uses the internet to support the provision of flexible dynamically scalable and on demand computing infrastructure for data and applications.

In academia, CC is a highly influential tool that can provide universities great 
scalability and flexibility, meaning that students, staff, faculty and administrators among other users are able to access and share university applications and data from various devices, such as personal computers and mobile smart devices anytime anywhere [31]. In view of Okai et al. [36], CC technology is now considered the silver bullet of educational technology. Therefore, universities, particularly those in more developed countries have started to adopt CC for various reasons, such as providing cost efficiency, increased collaboration, greater access to shared cloud applications and data, and greater scalability and flexibility for students, staff, faculty and administrators among other users, and to eventually provide enhanced academic outputs [37].

Although there are numerous benefits of CC, a number of authors have stressed the challenges that could potentially discourage HEIs from considering the technology as a solution for enhancing their existing IS to support their educational operations, such as teaching and research, thereby resulting in low rates of adoption [38]. According to a recent Cisco study, only 22 percent of cloud services are used in the education sector [39]. The rejection of the cloud is also due to users' unfamiliarity with services [28] [29]. Selection of CC as a solution to enhance existing IS can be a difficult and complex decision making process that cannot be performed overnight.

HEIs face several challenges that can hinder their IS development. Legal jurisdiction, privacy and regulatory compliance, reliability of the cloud service provider security and confidentiality of data, unexpected inaccessibility and vendor lock-in are among the most significant challenges that can discourage HEIs from considering CC as an IS development solution [28] [29] [38] [40]. Similarly, the findings of a survey conducted by the Carnegie Mellon University, USA, found that the challenges facing HEIs were not restricted to the challenges mentioned above, but the undeveloped and un-proven nature (IT maturity) of CC given its relative newness is another concern for the institution [22] [41].

The most talked about and key challenge of CC is security, since the institutions valuable data now resides beyond their firewalls. This encourages hacking and other malicious attacks on the cloud providers infrastructure where the data is stored [22] [29] [42] [43] [44] [45]. Not only that, HEIs are unware of how the cloud provider is handling their data during the migration and transference process, which can create trust issues between the cloud consumer (HEIs) and provider. Cloud providers who fail to comply with the service level agreement (SLA) further justify the low rate of CC adoption among HEIs [46], since the performance of the cloud service will be greatly affected because of the cloud provider failing to address the requirements of the SLA.

CC is an attractive prospect to HEIs given the benefits it can bring not only in a technological sense, but also in an institutional (organisational) and personal (users) sense as well. The above statistics are rather alarming, since only 22 percent of the world's HEIs are benefitting from CC [39], and given low rate of adoption. More research needs to be done on familiarising HEIs with CC and its 
potential benefits, as well as to educate them about the challenges and how overcome them. Despite the latter, research specific to the benefits and challenges of CC that could potentially support/hinder HEIs IS development is rather limited, and demonstrates a lack of evidence on the wide use of CC in HEIs. It has only been within the currentdecade that the literature on CC in the HEI context has started to emerge in IS literature [29].

Despite CC being a relatively new phenomenon in HEIs, some universities have successfully overcome the barriers that can potentially hinder their decision. Some universities have even accepted cloud technology, while also bearing in mind the most significant risks that can arise after post-implantation, such as security and trust. Furthermore, it appears that those universities who are currently utilising have applied their own cloud framework or roadmap as a guide to overcome adoption and integration barriers and embrace the benefits leading to the successful development of their existing IS. In the case study of Greenwich University, they introduced a service model, Education as a Service (EaaS) that helped to transform how their educational services and operations are delivered to their students. It was found that the model not only supported the university to accept and implement CC, but also demonstrated a number of benefits, such as simple consolidation of existing resources and services, and improving students learning satisfaction, and teachers' instruction. Not only that, students were keen to learn and undertake coursework, thereby further improving students learning experience. In short, there needs to be more success cases like the one at Greenwich University, but due to the unfamiliarity of CC among HEIs, as well as the challenges that could potentially hinder their IS development, is still a key issue within the HE sector.

HEIs often undergo a step-by-step process before deciding to adopt an educational cloud including: planning, deployment model selection, selecting the most appropriate service models, vendor selection, negotiating the SLA, migration, and integration strategy [36]. This also takes into account the various stakeholders, such as students, staff, faculty and administrators that support their institution productively and efficiently. The main purpose of HEIs adopting the education cloud is usually down to economic reasons. The lack of budget and resources due to public sector cuts can lead to long-term consequences, thereby affecting the level of service HEIs provide. For example, the Washington State University's School of Electrical Engineering and Computer Science (EECS) had faced significant cuts in its budget. Nevertheless, the EECS asserted that in spite of the current state of the economy, CC enabled them to expand the services they provide to students and faculty [22]. In short, the educational cloud aims to provide a cost-efficient, scalable and flexible technological infrastructure that helps to efficiently manage data and applications, provide better educational services, and teaching and learning experiences for students, staff, faculty and administrators.

Universities can also take advantage of various benefits. The literature identifies some of the general benefits that can support IS development in HEIs. CC is 
a system that uses a network of services hosted remotely on the internet as a means of storing, managing and processing data, as opposed to a local machine or server [23]. There are also various intangible benefits of the cloud, such as cost efficiency, increased collaboration, flexibility and scalability, and greater reliability and accessibility [29] [46] [47] [48] [49].

By reviewing the above studies, it can be deduced that the main benefits of the educational cloud, include:

$>$ Cost efficiency through the pay per use payment model, free software and switching to some greener IT solutions;

$>$ Improved accessibility to institutional resources using various devices anytime anywhere;

$>$ Increasing functional capabilities;

$>$ Offline usage and synchronisation;

$>$ Supports teaching and learning, and collaboration among faculty and students.

In the HE sector, one has to consider that the technology itself does not give them a competitive advantage given the rapid developments that occur within this environment. It is the users and the institution who provides this competitive advantage as there needs to be some level of interaction with the cloud system in order for it to perform the benefits that it sets out to achieve. To address the current IS problem facing UK HE, namely monitoring and progression systems employed at UK Universities (e.g. MyPGR), this paper introduces a CC model called "Educational Monitoring and Progression as a Service" (EMPaaS). This model combines the elements of monitoring and progression systems, such as MyPGR and applies them to a more flexible and scaleable cloud system that can be used as an educational service (see Figure 2).

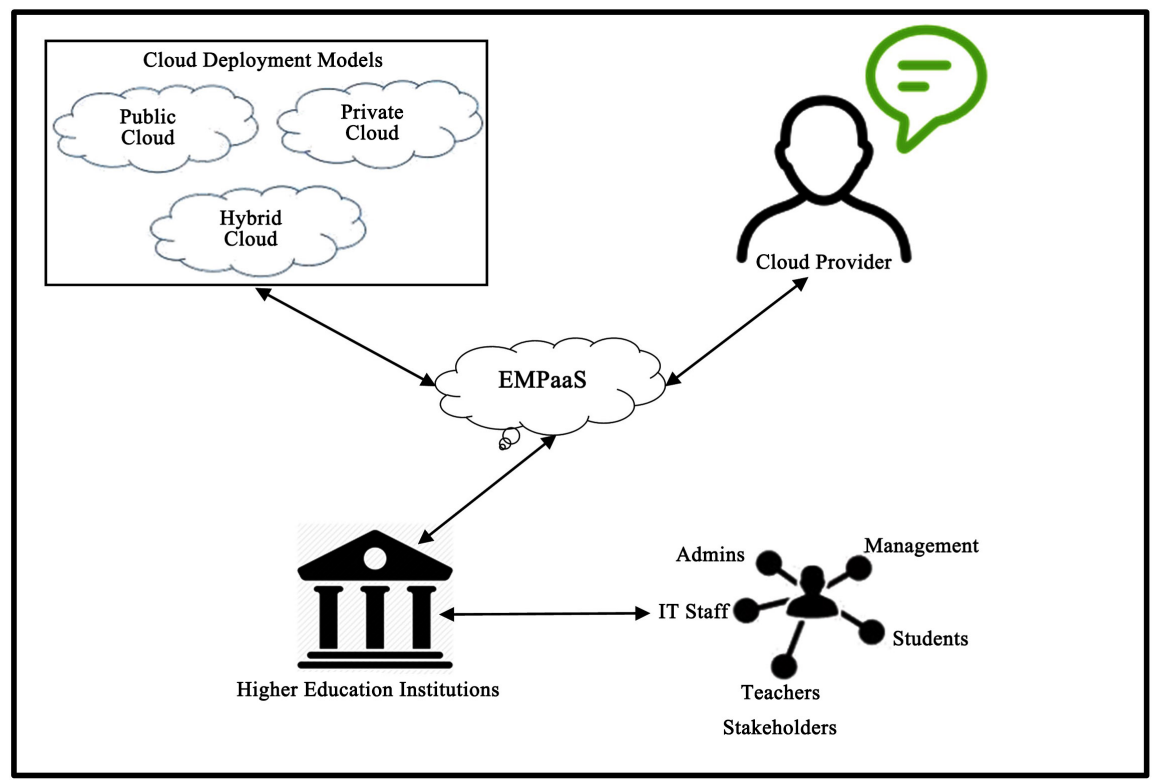

Figure 2. EMPaaS solution for HE to improve monitoring and progression processes, in addition to educational practices, such as teaching, research and course management. 
Here, students (as an example) can use the cloud to monitor their progression and key milestones relating to their PGR programme as they usually would with MyPGR. Only this time, students can use free cloud applications, such as "Google Apps for Education" to keep track of milestones and progressions; cloud apps within Google include Google Classroom, Google Calendar and Google Docs. Not only are these apps highly accessible and flexible, they are also free of charge, thus helping Universities to save money in the long-term.

CC can also be utilised into a course curriculum in disciplines ranging from technical and environmental sciences to the natural and social sciences. In the technical sciences. For example, CC could be used to facilitate technical projects such as systems development and programming through content hosting and sharing technical ideas with colleagues in order to promote project efficiency and ultimately improve the success rate of the projects. The sharing of content over a data centralisation and hosting service could also encourage open discourse about various subjects related to technical projects like coding and systems design in order to improve the outcomes of future projects that are part of the course syllabus. In the context of EMPaaS, student could use the cloud driven monitoring and progression system to plan project deliverables in the curriculum by using Google Apps for Education among other services. Putting this into context demonstrates how cost-effective and efficient cloud services can be owing to significant cost reductions by using free to use cloud tools. This applied across the various disciplines and their respect curriculums could yield tremendous cost savings. This would allow Universities to invest the money saved to potentially improve other areas of concern, such as the quality of teaching and research. This suggests that HEIs have a promising future, particularly with the rapid developments in educational technologies to facilitate their teaching, course management and research processes. CC is one such technology that leads to a gateway of opportunities for HEIs to develop their educational practices through highly accessible and efficient collaborative sharing platforms.

\section{Conclusions}

This paper explored the current state of HE, as well as current systems employed in Universities. MyPGR was used a case study to highlight the existing IS problem facing HEIs. CC was then introduced as viable IS solution to enhance existing IS to address the current issues with this monitoring and progression from multiple stakeholder perspectives. This paper proposed the "Educational Monitoring and Progression as a Service" model as a potential cloud solution to monitoring and progression systems, such as MyPGR, which promotes collaborative sharing capabilities to ultimately enhance educational practices, such as teaching, research and management in HEIs. EMPaaS can potentially provide the following benefits and opportunities:

$>$ Helping to monitor student progression and key milestones relating to their PGR programme; 
Enabling students to use free cloud applications to keep track of milestones and progressions;

Highly accessible and flexible cloud applications;

Cost-effectiveness to enable UK Universities to pursue other important investments.

In short, the success of the educational cloud depends on not just the technological perspective, but the perspective of the institution and users of the technology. Therefore, it is important that when considering CC as a means to develop existing IS, HEIs must take into consideration all of the stakeholders who will be using the technology, as well as the overall impact it will have on the institution before looking at the benefits once accepted.

\section{Conflicts of Interest}

The authors declare no conflicts of interest regarding the publication of this paper.

\section{References}

[1] O'Prey, P. (2015) Patterns and Trends in UK Higher Education 2015.

[2] Mayhew, K. (2017) UK Higher Education and Brexit. Oxford Review of Economic Policy, 33, S155-S161. https://doi.org/10.1093/oxrep/grx012

[3] Mellors-Bourne, R., Humfrey, C., Kemp, N. and Woodfield, S. (2013) The Wider Benefits of International Higher Education in the UK. https://www.gov.uk/government/uploads/system/uploads/attachment_data/file/24040 7/bis-13-1172-the-wider-benefits-of-international-higher-education-in-the-uk.pdf

[4] Mercer, J. (2015) The Key Issues Facing the UK Higher Education Sector. http://www2.deloitte.com/content/dam/Deloitte/uk/Documents/public-sector/deloi tte-uk-making-the-grade-2015.pdf

[5] Grove, J. (2015) 7 Key Challenges for UK Higher Education. https://www.timeshighereducation.com/carousels/7-key-challenges-uk-higher-educ ation

[6] Ali, M.B., Wood-Harper, T. and Mohamad, M. (2018) Benefits and Challenges of Cloud Computing Adoption and Usage in Higher Education: A Systematic Literature Review. International Journal of Enterprise Information Systems, 14, 64-77. https://doi.org/10.4018/IJEIS.2018100105

[7] Lock, H. (2015) Six Ways Higher Education Benefits the UK Economy. http://www.theguardian.com/higher-education-network/2015/jul/09/six-ways-high er-education-benefits-the-uk-economy

[8] Jackson, A. (2016) A New Study Found a Promising Link between the Number of Universities in a Country and GDP.

https://www.businessinsider.com/link-between-universities-in-a-country-and-gdp2016-8? $\mathrm{r}=\mathrm{US} \& \mathrm{IR}=\mathrm{T}$

[9] UCAS (2018) A Record Percentage of Young People Are off to University. https://www.ucas.com/corporate/news-and-key-documents/news/record-percentag e-young-people-are-university

[10] Top Universities (2019) The World's Top 100 Universities. https://www.topuniversities.com/student-info/choosing-university/worlds-top-100- 
$\underline{\text { universities }}$

[11] Yorke, M. and Longden, B. (2008) The First-Year Experience of Higher Education in the UK. Higher Education Academy.

https://www.heacademy.ac.uk/system/files/fyefinalreport_0.pdf

[12] BIS (2009) Higher Ambitions: The Future of Universities in a Knowledge Economy. http://www.employability.ed.ac.uk/documents/Staff/PoliciesReports/BIS-HigherAm bitions-Summary-Nov2009.pdf

[13] Denham, J. (2008) Demographic Change and Its Impact on the Higher Education Sector in England. Department for Innovation, Universities and Skills (DUIS), 1-150.

[14] Parr, C. (2015) 6 Challenges Impeding Technology Adoption in Higher Education in 2014.

https://www.timeshighereducation.com/news/6-challenges-impeding-technology-a doption-in-higher-education-in-2014/2011501.article

[15] Hall, R. and Stahl, B. (2012) Against Commodification: The University, Cognitive Capitalism and Emergent Technologies. Open Access Journal for a Global Sustainable Information Society, 10, 184-202. https://doi.org/10.31269/vol10iss2pp184-202

[16] Higgins, S., Xiao, Z. and Katsipataki, M. (2012) The Impact of Digital Technology on Learning: A Summary for the Education Endowment Foundation. Education Endowment Foundation and Durham University, Durham.

[17] Checkland, P. (1999) Systems Thinking, Systems Practice. John Wiley, Hoboken, NJ.

[18] Checkland, P. (2000) Soft Systems Methodology: A Thirty Year Retrospective. Systems Research and Behavioral Science, 17, S11.

[19] Wilson, B. (2001) Soft Systems Methodology: Conceptual Model Building and Its Contribution. Wiley, Hoboken, NJ.

[20] Burge, S. (2015) An Overview of the Soft Systems Methodology. System Thinking: Approaches and Methodologies, 1-14.

[21] Wilson, B. and Van Haperen, K. (2015) Soft Systems Thinking, Methodology and the Management of Change. Palgrave Macmillan, London.

[22] Sultan, N. (2010) Cloud Computing for Education: A New Dawn? International Journal of Information Management, 30, 109-116. https://doi.org/10.1016/j.ijinfomgt.2009.09.004

[23] Mell, P. and Grance, T. (2009) The NIST Definition of Cloud Computing. National Institute of Standards and Technology, 50.

[24] Alabbadi, M.M. (2011) Cloud Computing for Education and Learning: Education and Learning as a Service (ELaaS). 2011 14th International Conference on Interactive Collaborative Learning, Piestany, Slovakia, 21-23 September 2011, 589-594. https://doi.org/10.1109/ICL.2011.6059655

[25] Youssef, A.E. and Alageel, M. (2012) A Framework for A Framework for Secure Cloud Computing. International Journal of Computer Science Issues, 9, 487-500.

[26] Halpert, B. (2011) Auditing Cloud Computing: A Security and Privacy Guide. Wiley, Hoboken, NJ. https://doi.org/10.1002/9781118269091

[27] Eviwiekpaefe, A.E. and Ajakaiye, F. (2014) The Trend and Challenges of Cloud Computing: A Literature Review. International Letters of Social and Humanistic Sciences, 16, 13-20. https://doi.org/10.18052/www.scipress.com/ILSHS.16.13

[28] Ali, M. (2019) The Barriers and Enablers of the Educational Cloud: A Doctoral Stu- 
dent Perspective. Open Journal of Business and Management, 7, 1-24. https://doi.org/10.4236/ojbm.2019.71001

[29] Ali, M. (2019) Cloud Computing at a Cross Road: Quality and Risks in Higher Education. Advances in Internet of Things, 9, 33-49. https://doi.org/10.4236/ait.2019.93003

[30] Durkee, D. (2010) Why Cloud Computing Will Never Be Free. Communications of the ACM, 53, 62-69. https://doi.org/10.1145/1735223.1735242

[31] Ali, M.B. (2019) Multiple Perspective of Cloud Computing Adoption Determinants in Higher Education a Systematic Review. International Journal of Cloud Applications and Computing (IJCAC), 9, 89-109. https://doi.org/10.4018/IJCAC.2019070106

[32] Jian, A. and Pandy, U.S. (2013) Role of Cloud Computing in Higher Education. International Journal of Advanced Research in Computer Science and Software Engineering, 3, 966-972.

[33] Ahronovitz, M., et al. (2010) Cloud Computing Use Cases White Paper. Cloud Computing Use Case Discussion Group.

[34] Nandgaonkar, S.V. and Raut, A.B. (2014) A Comprehensive Study on Cloud Computing. International Journal of Computer Science and Mobile Computing, 3, 733-738.

[35] Ramgovind, S., Eloff, M.M. and Smith, E. (2010) The Management of Security in Cloud Computing. 2010 Information Security for South Africa, Sandton, Johannesburg, 2-4 August 2010, 1-7. https://doi.org/10.1109/ISSA.2010.5588290

[36] Mircea, M. and Andreescu, A.I. (2011) Using Cloud Computing in Higher Education: A Strategy to Improve Agility in the Current Financial Crisis. Communications of the IBIMA, 2011, Article ID: 875547. https://doi.org/10.5171/2011.875547

[37] Okai, S., Uddin, M., Arshad, A., Alsaqour, R. and Asadullah Shah. (2014) Cloud Computing Adoption Model for Universities to Increase ICT Proficiency. SAGE Open, 4, 1-10. https://doi.org/10.1177/2158244014546461

[38] Ercan, T. (2010) Effective Use of Cloud Computing in Educational Institutions. Procedia-Social and Behavioral Sciences, 2, 938-942. https://doi.org/10.1016/j.sbspro.2010.03.130

[39] Alharthi, A., Yahya, F., Wills, G. and Walters, R.J. (2015) An Overview of Cloud Services Adoption Challenges in Higher Education Institutions. Proceedings of the 2nd International Workshop on Emerging Software as a Service and Analytics, 102-109.

[40] Moore, M. (2015) Cisco Predicts 'Second Wave' of Cloud Adoption. http://www.techweekeurope.co.uk/cloud/cloud-management/cisco-second-wave-cl oud-adoption-175535

[41] Alshuwaier, F.A., Alshwaier, A.A. and Areshey, A.M. (2012) Applications of Cloud Computing in Education. Computing and Networking Technology. 2012 8th International Conference on Computing and Networking Technology, Gueongju, South Korea, 27-29 August 2012, 26-33.

[42] Sultan, N.A. (2011) Reaching for the "Cloud": How SMEs Can Manage. International Journal of Information Management, 31, 272-278.

https://doi.org/10.1016/j.ijinfomgt.2010.08.001

[43] Sun, Y., Zhang, J., Xiong, Y. and Zhu, G. (2014) Data Security and Privacy in Cloud Computing. International Journal of Distributed Sensor Networks, 2014, 1-9. https://doi.org/10.1155/2014/190903 
[44] Shakeabubakor, A.A., Sundararajan, E. and Hamdan, A.R. (2015) Cloud Computing Services and Applications to Improve Productivity of University Researchers. International Journal of Information and Electronics Engineering, 5, 153-157. https://doi.org/10.7763/IJIEE.2015.V5.521

[45] Ramachandra, G., Iftikhar, M. and Khan, F.A. (2017) A Comprehensive Survey on Security in Cloud Computing. Procedia Computer Science, 110, 465-472. https://doi.org/10.1016/j.procs.2017.06.124

[46] Kouatli, I. (2016) Managing Cloud Computing Environment: Gaining Customer Trust with Security and Ethical Management. Procedia Computer Science, 91, 412-421. https://doi.org/10.1016/j.procs.2016.07.110

[47] Rittinghouse, J.W. and Ransome, J.F. (2017) Cloud Computing: Implementation, Management, and Security. CRC Press, Boca Raton, FL.

https://doi.org/10.1201/9781439806814

[48] Chang, V. (2015) Delivery and Adoption of Cloud Computing Services in Contemporary Organizations. IGI Global, Hershey, PA.

https://doi.org/10.4018/978-1-4666-8210-8

[49] Mokhtar, S.A., Al-Sharafi, A., Shaikh Ali, S.H. and Al-Othmani, A.Z. (2016) Identifying the Determinants of Cloud Computing Adoption in Higher Education Institutions. 2016 International Conference on Information and Communication Technology, Kuala Lumpur, Malaysia, 16-17 May 2016, 115-119.

https://doi.org/10.1109/ICICTM.2016.7890787 